\title{
Disrupting Sensitization of Transient Receptor Potential Vanilloid Subtype 1 Inhibits Inflammatory Hyperalgesia
}

\author{
Michael J. M. Fischer, ${ }^{1,2 \star}$ Joan Btesh, ${ }^{1 \star}$ and Peter A. McNaughton ${ }^{1}$ \\ ${ }^{1}$ Department of Pharmacology, University of Cambridge, Cambridge, CB2 1PD, United Kingdom, and ${ }^{2}$ Institute of Physiology and Pathophysiology, \\ University of Erlangen-Nuremberg, D-91054 Erlangen, Germany
}

\begin{abstract}
Transient receptor potential vanilloid subtype 1 (TRPV1) is a heat-sensitive ion channel that plays a key role in enhanced pain sensation after inflammation, but directly blocking TRPV1 causes hyperthermia and decreased sensitivity to painful levels of heat in animals and humans. Here we explore an alternative analgesic strategy in which the modulation of TRPV1 is inhibited by antagonizing the interaction between TRPV1 and A kinase anchoring protein 79 (AKAP79), a scaffolding protein essential for positioning serine-threonine kinases adjacent to target phosphorylation sites. We first defined key residues in the domain in TRPV1 that interacts with AKAP79, and we then used this information to construct short peptides capable of preventing TRPV1-AKAP79 interaction. An effective peptide, when coupled to a TAT sequence conferring cell permeability, was found to be analgesic in three mouse models of inflammatory hyperalgesia. These results demonstrate the potential value of interfering with the interaction between TRPV1 and AKAP79 as a novel analgesic strategy.
\end{abstract}

\section{Introduction}

The transient receptor potential vanilloid receptor subtype 1 (TRPV1) ion channel is activated by noxious temperatures above $43^{\circ} \mathrm{C}$ and is expressed in nociceptive (pain-eliciting) primary afferent nerve fibers (Caterina et al., 1997). Activation of TRPV1 by heat or by other activators, such as capsaicin, the active ingredient of chili peppers, causes a sensation of burning pain. Heat hyperalgesia, in which the threshold for heat pain is lowered after inflammation or injury, was found to be reduced when TRPV1 was genetically deleted (Caterina et al., 2000; Davis et al., 2000), suggesting that blockers of TRPV1 will have value as novel analgesics. Two difficulties have emerged in trials of TRPV1 blockers, however: (1) block of peripheral TRPV1 causes hyperthermia, and (2) the heat threshold is elevated, which could lead to accidental burns (Gavva et al., 2007; Papakosta et al., 2011; Vay et al., 2012). These problems have essentially halted development of TRPV1 blockers as analgesics. In the present study, we develop an alternative strategy for inhibiting inflammatory hyperalgesia caused by TRPV1, namely blocking phosphorylation of TRPV1 rather than blocking the channel itself.

Inflammation leads to the release of a range of extracellular mediators, including bradykinin, prostaglandin $\mathrm{E}_{2}$, and nerve growth factor, which lower the heat activation threshold of TRPV1 by activating cellular kinases whose action is to phosphorylate TRPV1 (Cesare and McNaughton, 1996; Fischer et al., 2010). The reaction speeds and specificities of kinases are in many

\footnotetext{
Received Aug. 3, 2012; revised Feb. 21, 2013; accepted March 1, 2013.

Author contributions: M.J.M.F., J.B., and P.A.M. designed research; M.J.M.F. and J.B. performed research;

M.J.M.F., J.B., and P.A.M. analyzed data; M.J.M.F., J.B., and P.A.M. wrote the paper.

*M.J.M.F. and J.B. contributed equally to this work.

Correspondence should be addressed to Prof. Peter A. McNaughton, Department of Pharmacology, University of Cambridge, Tennis Court Road, CB2 1PD Cambridge, UK. E-mail: pam42@cam.ac.uk.

DOI:10.1523/JNEUROSCI.3721-12.2013

Copyright $\odot 2013$ the authors $\quad 0270-6474 / 13 / 337407-08 \$ 15.00 / 0$
}

cases enhanced by scaffolding proteins whose function is to assemble a signaling complex of kinases together with a target substrate. The A kinase anchoring protein (AKAP) family of scaffolding proteins were originally named for their ability to target PKA to appropriate substrates but are now known to assemble signaling complexes of other kinases, such as PKC (Welch et al., 2010; Sanderson and Dell'Acqua, 2011). AKAP79 (rodent homolog AKAP150), which has binding sites for both PKA and $\mathrm{PKC}$, is coexpressed with TRPV1 in small nociceptive sensory neurons (Zhang et al., 2008; Brandao et al., 2012). AKAP79 binds to TRPV1 and is essential for PKA- and PKC-dependent sensitization of TRPV1 (Schnizler et al., 2008; Zhang et al., 2008; Jeske et al., 2009). The binding site for AKAP79 on TRPV1 has been located within amino acids 736-749 in the TRPV1 C-terminal domain (Zhang et al., 2008). In the present study, we define critical residues within this binding site, and we show that peptide antagonists to TRPV1-AKAP79 binding can disrupt sensitization of TRPV1 in vitro. A cell-permeable peptide antagonist can effectively abrogate inflammatory hyperalgesia in vivo.

\section{Materials and Methods}

Plasmids, mutagenesis, and cloning. Human TRPV1 subcloned into the pCDNA3-V5-His-TOPO vector (Invitrogen) was used (Zhang et al., 2008). Human AKAP79 was obtained from Dr. John Scott (University of Washington, Seattle, WA). Site-directed mutagenesis was performed via the QuikChange II XL kit (Stratagene) according to the recommended protocol. All cDNA constructs were confirmed by sequencing.

Cell culture and transfection. Dorsal root ganglia (DRGs) were harvested from C57BL/ 6 mice of either sex aged 6-12 weeks and were transferred into DMEM (Invitrogen). Ganglia were treated with $0.25 \%$ collagenase type IV (Invitrogen) for $1 \mathrm{~h}$ and subsequently dissociated using pipette tips of decreasing tip diameter, plated on dishes or coverslips coated with poly-L-lysine and laminin ( $1 \mathrm{mg} / \mathrm{ml}$; Sigma), and cultured in DMEM supplemented with $60 \mu \mathrm{g} / \mathrm{ml}$ penicillin and $100 \mu \mathrm{g} / \mathrm{ml}$ streptomycin (Invitrogen), $200 \mu \mathrm{g} / \mathrm{ml}$ glutamine (Invitrogen), 10\% fetal bovine serum, and $2.5 \mathrm{~S}$ mouse NGF $(100 \mathrm{ng} / \mathrm{ml}$; Alomone Labs $)$ at $37^{\circ} \mathrm{C}$ 
and 5\% $\mathrm{CO}_{2}$. Electrophysiological recordings were performed within $2 \mathrm{~d}$ of dissociation. HEK 293 cells were cultured at $37^{\circ} \mathrm{C}$ and $5 \% \mathrm{CO}_{2}$ as above but without NGF. HEK293 cells were transferred into antibiotic- and serum-free medium before transfection (Lipofectamine 2000 from Invitrogen or Metafectene from Biontex) according to the protocol of the manufacturer. After $6-10 \mathrm{~h}$, cells were replated at suitable density onto coverslips or $35 \mathrm{~mm}$ dishes precoated with poly-L-lysine $(1 \mathrm{mg} / \mathrm{ml})$. For patch-clamp experiments, HEK293 cells were cotransfected with GFP (1:3 ratio). TRPV1 transfection typically caused a more rounded morphology than is normal in HEK293 cells, particularly in highly expressing cells (see Fig. 3), but TRPV1-expressing cells continued to be viable in culture.

Immunocytochemistry, confocal microscopy, and image analysis. To define the location of the plasma membrane, HEK293 cells were stained with wheat germ agglutinin (WGA)-Alexa Fluor $594(5 \mu \mathrm{g} / \mathrm{ml})$ for 10 min on ice. Cells were then fixed with $4 \%$ paraformaldehyde and $0.2 \%$ glutaraldehyde in PBS at room temperature for $20 \mathrm{~min}$. Cells were permeabilized with $0.2 \%$ saponin, and nonspecific binding was blocked with $0.1 \%$ fish skin gelatin. HEK293 cells expressing TRPV1 were stained with mouse anti-V5 antibody (1:1000; Invitrogen) for $3 \mathrm{~h}$ and Alexa Fluor 488 anti-mouse secondary (1:500; Molecular Probes) for $1 \mathrm{~h}$. Images were acquired on a Leica SP 5 confocal microscope with a $63 \times$ plan apochromatic oil-immersion objective (numerical aperture 1.4). The pinhole was set to a diameter corresponding to 1 Airy unit. Alexa Fluor 488 was excited by the $488 \mathrm{~nm}$ line of an argon-ion laser and emission was detected in the range of 498-586 nm; WGA-Alexa Fluor 594 was excited with a $543 \mathrm{~nm}$ helium-neon laser and emission was detected at 586-690 $\mathrm{nm}$. Cells were sampled fourfold in line-scanning mode, separately for all fluorophores. Analysis was performed using NIH ImageJ (http://rsb. info.nih.gov/ij/). Regions of interest (ROIs; see Fig. 3) were generated to measure average cytosolic and plasma membrane fractions of TRPV1 and its mutants. The plasma membrane location was determined by thresholding the WGA image, with subsequent dilation and erosion to provide a smooth ROI (see Fig. $3 A$ ). The cytoplasmic ROI excludes the nucleus, which had a lower fluorescence intensity.

Coimmunoprecipitation. AKAP79 and TRPV1 mutants were expressed separately in HEK293 cells for 24-48 h. Protein was harvested in ice-cold isotonic Tris-Na buffer (20 mm Tris and $150 \mathrm{~mm} \mathrm{NaCl}$ ), 1\% NP-40, and $10 \%$ proteinase inhibitor cocktail (Roche). Whole-cell extracts were mixed for $1 \mathrm{~h}$ with anti-V5 antibody (Invitrogen) and then incubated overnight at $4^{\circ} \mathrm{C}$ with Protein A agarose beads previously blocked with $0.5 \%$ BSA. The immunocomplex was pulled down by centrifugation at $12,000 \times g$ and washed three times with ice-cold lysis buffer before dissociation at $100^{\circ} \mathrm{C}$ with Laemmli's sample buffer (Sigma) before running on a Western blot. Bands were detected with anti-AKAP79 (Santa Cruz Biotechnology), and the blot was stripped and reprobed with mouse anti-V5 antibody (Invitrogen). Analysis was performed using NIH ImageJ. Precipitation was normalized to the respective TRPV1-V5 intensity and compared with the wild type (WT).

Calcium imaging. HEK293 cells on coverslips were loaded with fura-2 $\mathrm{AM}(3 \mu \mathrm{M})$ in the presence of $0.02 \%$ pluronic F-127 (both from Invitrogen) for $30 \mathrm{~min}$, placed into a glass-bottomed dish, and mounted on a Nikon Eclipse Ti-E inverted microscope with a $10 \times$ Plan Fluor objective. Cells were continuously superfused with gravity-driven HEPES-buffered extracellular solution (in mM: $140 \mathrm{NaCl}, 5 \mathrm{KCl}, 2 \mathrm{CaCl}_{2}, 2 \mathrm{MgCl}_{2}, 10$ HEPES, and 10 glucose, adjusted to $\mathrm{pH}$ 7.4) or test solutions through a common outlet. Protocols were pre-programmed and applied via controlling pinch valves (CV Scientific). Cells were illuminated with a monochromator alternating between $340 \pm 10$ and $380 \pm 10 \mathrm{~nm}$ (OptoScan; Cairn Research), controlled by WinFluor 3.2 software (Dr. John Dempster, University of Strathclyde, Glasgow, UK). Pairs of images were acquired every $2 \mathrm{~s}$ with $100 \mathrm{~ms}$ exposure time using an iXon $897 \mathrm{EM}-\mathrm{CCD}$ camera (Andor Technology). Image time series were converted to .tiff and processed by an NIH ImageJ macro. Images of the background intensity were calculated for both wavelengths by a median filter and subtracted from the respective image stack. Capsaicin-responsive cells were identified by summing the maximum increase at $340 \mathrm{~nm}$ and the decrease at $380 \mathrm{~nm}$ after the fourth capsaicin application. ROIs were adapted to these cells and were used to calculate fluorescence ratios, followed by transformation to calcium levels (Grynkiewicz et al., 1985). The average time course of calcium changes in all capsaicin-responsive cells was calculated as mean \pm SEM (see Figs. $1 B, 2 A$ ). For every cell, the calcium increase $\left(\Delta[\mathrm{Ca}]_{\mathrm{i}}\right)$ after application of capsaicin was calculated between the baseline (over $10 \mathrm{~s}$ immediately before application of capsaicin) and peak calcium reached within $60 \mathrm{~s}$ after capsaicin application. In experiments to measure the sensitizing effects of PKC activation (see Fig. $2 A)$, capsaicin ( $200 \mathrm{~nm}$ ) was applied for $1 \mathrm{~s}$ six times at intervals of $5 \mathrm{~min}$, and after the fourth capsaicin application, phorbol myristate acetate (PMA) $(1 \mu \mathrm{M})$ was applied for $180 \mathrm{~s}$. Sensitization was calculated as the ratio of $\Delta[\mathrm{Ca}]_{\mathrm{i}}$ after the sixth and fourth capsaicin applications. Sensitization of TRPV1 measured in this way is not affected to a significant extent by processes such as calcium release from the endoplasmatic reticulum or influx through voltage-gated ion channels (Bonnington and McNaughton, 2003). An additional consideration was that calcium transport and buffering processes, which vary among different TRPV1expressing neurons, affect later stages of the response time course but have little effect on the peak response (Lu et al. 2006). At the end of all protocols, the calcium ionophore ionomycin $(5 \mu \mathrm{M})$ was applied to saturate $[\mathrm{Ca}]_{\mathrm{i}}$

Patch-clamp recording. Whole-cell voltage clamp was performed on small-diameter DRG neurons ( $<20 \mu \mathrm{m}$ diameter). Membrane currents were acquired with an Axopatch 200B amplifier (Molecular Devices), low-pass filtered at $1 \mathrm{kHz}$, and sampled at $2 \mathrm{kHz}$. Glass electrodes (GB150F-8P; Science Products) were fabricated (P-97; Sutter Instruments) and heat polished on a microforge (MF-830; Narishige) for a final resistance of 2.5-5.0 M $\Omega$. To limit capsaicin-induced currents, the external sodium was reduced to $30 \mathrm{~mm}$, substituted by $N$-methyl-D-glucamine $(110 \mathrm{~mm})$, and titrated with $\mathrm{HCl}$. The internal solution contained the following (in mM): $140 \mathrm{KCl}, 2 \mathrm{MgCl}_{2}, 5 \mathrm{EGTA}$, and $10 \mathrm{HEPES}$, adjusted to $\mathrm{pH}$ 7.2. All experiments were performed at room temperature and a holding potential of $-60 \mathrm{mV}$. Heat stimulation was performed with a linear ramp from $22^{\circ} \mathrm{C}$ to $44-45^{\circ} \mathrm{C}$ within $5 \mathrm{~s}$ applied every $45 \mathrm{~s}$ by a heat filament driven by a WAS02 device (Dittert et al., 2006). The pClamp 10 software (Molecular Devices) was used for acquisition and offline analysis. Capsaicin was applied every $45 \mathrm{~s}$ for a period of $5 \mathrm{~s}$. After an initial tachyphylaxis to the first two applications, no trend in maximum current amplitude was observed from the third to the seventh applications (see Fig. $4 A$ ).

Chemicals. Peptides with at least $80 \%$ purity and HPLC and mass spectroscopy confirmation were obtained from Biomatik. Transmembrane uptake of peptides interfering with the TRPV1-AKAP79 interaction was promoted by coupling to TAT (transactivator of transcription of HIV, which contains a series of positively charged amino acids). The negative charges at positions 737 and 738 of peptides mimicking the TRPV1 binding domain (amino acid numbering for hTRPV1) as well as the strongly positively charged C-terminal end of TAT favored addition of TAT to the C-terminal end, generating 736-745-TAT (KDDYRWCF RVYGRKKRRQRRR). The scrambled sequence was RFVCWDKYRDYG RKKRRQRRR (scramble-TAT). Capsaicin and PMA were obtained from Sigma-Aldrich.

Behavioral experiments. Male mice (strain C57BL/6) 6-12 weeks of age were used for behavioral experiments. Animals were kept in a temperature-controlled environment $\left(21^{\circ} \mathrm{C}\right)$ on a normal $12 \mathrm{~h}$ light/dark cycle and had food and water available ad libitum. For the Formalin test, mice were injected with of a test peptide in $20 \mu \mathrm{l}$ saline into the left plantar hindpaw, and after $30 \mathrm{~min}$, a formaldehyde solution (20 $\mu \mathrm{l}, 4 \%$ Formalin, $537 \mathrm{~mm}$ ) was injected into the same site. Mice were tested on opaque glass and observed through a mirror below. The total time spent lifting, licking and biting the injected paw was considered as pain-related behavior and was recorded in $5 \mathrm{~min}$ intervals from $5 \mathrm{~min}$ before to $60 \mathrm{~min}$ after injection (see Fig. 6A). For PMA-induced nociception, mice were habituated for $2 \mathrm{~h}$ in the test chambers. PMA (50 pmol/paw) and a test peptide were mixed and injected in $20 \mu \mathrm{l}$ saline into the left plantar hindpaw. The total duration of licking and biting of the injected paw was considered as pain-related behavior (Ferreira et al., 2005). Animals were observed for $1 \mathrm{~h}$ after the injection (see Fig. 6B). For the Hargreaves test, mice were habituated for $\sim 1 \mathrm{~h}$ in the test chambers. To assess inflammatory heat hyperalgesia, a test peptide ( $10 \mu \mathrm{M}$ in saline, $20 \mu \mathrm{l})$ or saline (20 
$\mu \mathrm{l})$ was injected into the left hindpaw, and 30 min later, $\lambda$-carrageenan (2\% in saline, $20 \mu \mathrm{l})$ or saline $(20 \mu \mathrm{l})$ was injected at the same site. Paw-withdrawal latency during heating was measured by a fixed infrared stimulus (Ugo Basile). Maximum stimulus duration was $15 \mathrm{~s}$ to prevent tissue damage. Observers were blinded to the identity of test injections. All licensed procedures were approved by the United Kingdom Home Office.

Data analyses. Two independent groups of data containing $<10$ samples were compared using the nonparametric $U$ test. Two groups containing 10 samples or more were compared with a paired or unpaired $t$ test as appropriate. Repeated measurements and multiple groups were compared by ANOVA and honestly significant difference (HSD) post hoc tests. Statistical analysis was performed using Statistica 8 (Statsoft), and dose-response curves were fitted by the Hill equation in Origin 7.5 (OriginLab). Data are presented as mean \pm SEM; $p<0.05$ was considered significant. Significance levels are as follows: n.s., nonsignificant; ${ }^{\star} p<0.05 ;{ }^{\star *} p<0.01 ;{ }^{* *} p<0.001$.

\section{Results}

Amino acids in the range of 736-749 in the TRPV1 C-terminal domain have been shown to contain the AKAP79 binding site, and antagonism of the binding of AKAP79 to this domain abolishes sensitization of TRPV1 after activation of PKA or PKC (Zhang et al., 2008), but no details are known about critical amino acids within this binding site. Alanine mutants were constructed by site-directed mutagenesis to examine the importance of each individual amino acid in the TRPV1 binding site for AKAP79. Expression of all TRPV1 mutants was shown to be normal on Western blots (Fig. 1A). Functionality was then probed using calcium imaging and the TRPV1-specific agonist capsaicin (Fig. 1B,C). All alanine mutants except for D738A and R740A were found to be sensitive to capsaicin. Further mutation of R740 to $\mathrm{Q}$ generated a capsaicin-sensitive mutant. In the case of the aspartic acid at position 738, which is conserved across species, we found that none of the mutations to $\mathrm{S}, \mathrm{N}$, and $\mathrm{Q}$, were responsive to even elevated capsaicin $(2 \mu \mathrm{M})$, and it was therefore not possible to test the impact of a mutation of D738 in a direct sensitization assay.

The effect of these mutations on sensitization of TRPV1 was investigated by activating TRPV1 using brief applications of capsaicin in a calcium imaging assay and then observing the enhancement in activation of TRPV1 caused when PKC is activated by PMA (a potent and specific activator of PKC). The calcium imaging method provides a convenient measure of sensitization of TRPV1. Sensitization of WT TRPV1 by PKC activation was highly significant $(p<0.001$; Fig. $2 A$, ANOVA, HSD post hoc test). PKC-dependent sensitization was essentially unaffected by most alanine mutations (Fig. $2 B$ ) but was abolished with the mutants C742A and V745A, suggesting that these two amino acids locations play a critical role in the AKAP79-dependent sensitization of TRPV1.

Binding of AKAP79 to TRPV1 promotes trafficking of TRPV1 to the membrane in addition to its effect on sensitization (Zhang et al., 2008). Enhanced trafficking increases TRPV1 expression in the cell membrane but is a slower process than sensitization, which results mainly from an increase in the open probability of TRPV1 ion channels already in the membrane (Studer and McNaughton, 2010). The two measures of AKAP79-TRPV1 interaction are therefore essentially independent. We used immunocytochemistry to determine the effect of alanine mutations on the distribution of TRPV1 mutants between the cytoplasm and the plasma membrane. Figure $3 A$ shows that a ring of TRPV 1 expression was visible at the membrane location defined by the binding of WGA, although the resolution limit of light micros-
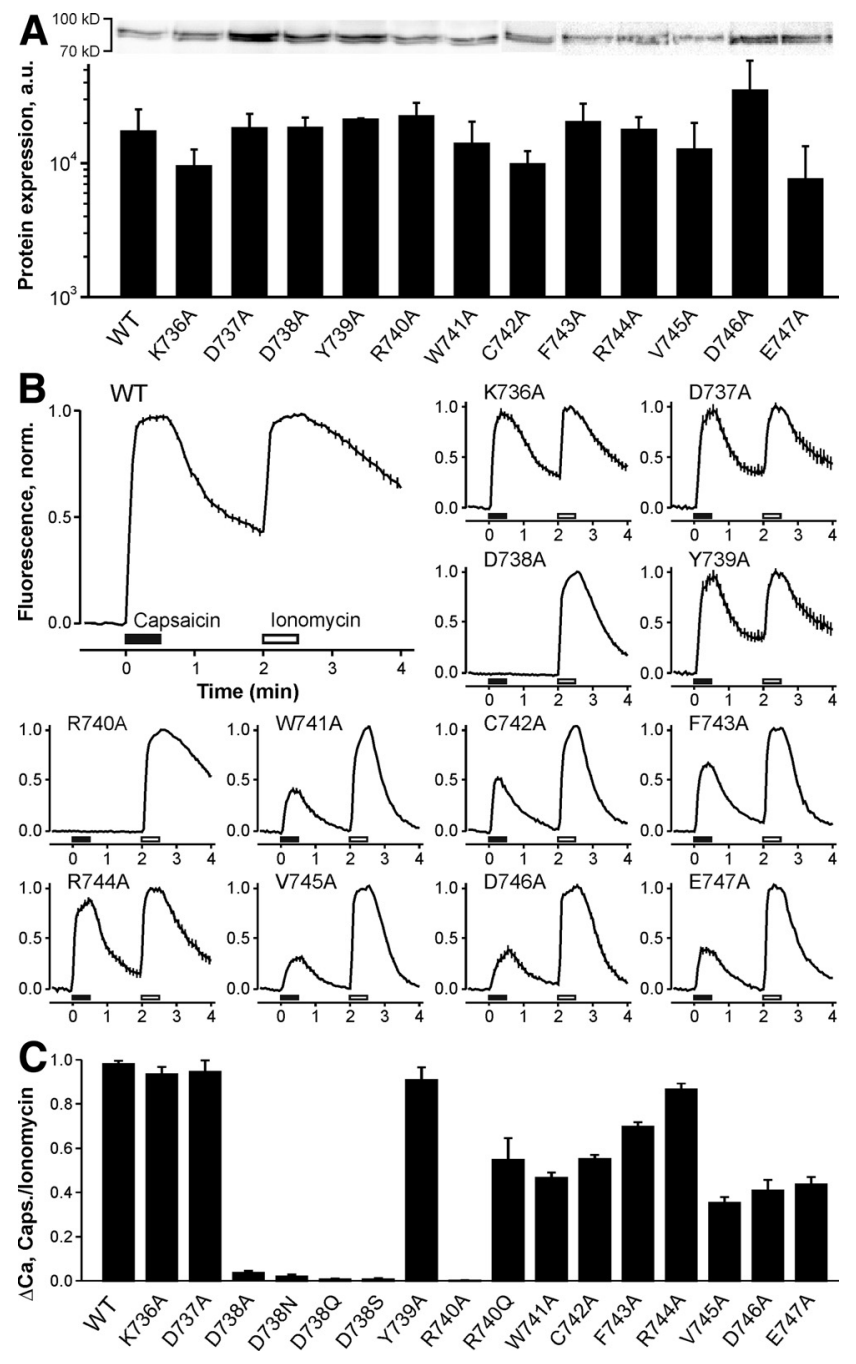

Figure 1. Expression and responses to capsaicin of TRPV1 mutants. $\boldsymbol{A}$, Top, Expression levels of TRPV1 alanine mutations in the range of 736-747 in HEK293 cells detected with anti-V5 in Western blots. Similar results obtained with all mutants in at least three experiments. $\boldsymbol{B}$, TRPV1 mutant channel function assessed from calcium increase in response to capsaicin ( $200 \mathrm{~nm}, 30 \mathrm{~s}$, black bars). Responses normalized to calcium increases evoked by ionomycin (open bars). Traces are averages \pm SEM of calcium signals from $n=37-129$ individual cells. $\boldsymbol{C}, \Delta[\mathrm{Ca}]_{\mathrm{i}}$ response to capsaicin ( $200 \mathrm{~nm}, 30 \mathrm{~s}$ ) relative to response to ionomycin for mutants shown in $\boldsymbol{B}$ and others. TRPV1 mutants D738A, Q and S, and R740A did not respond to capsaicin up to $5 \mu \mathrm{M}$, but $R 740 Q$ was capsaicin responsive.

copy means that this juxtamembrane region could also contain some signal from TRPV1 present in submembrane vesicles. $\mathrm{Mu}-$ tation of D738, R740, and C742 to alanine reduced trafficking of TRPV1 to the membrane when compared with WT (Fig. $3 B ; p<$ $0.001, p=0.001$, and $p=0.009$, respectively, ANOVA, HSD post hoc tests). Therefore, the trafficking experiments identify a group of amino acids partly overlapping those identified from sensitization experiments. The overlap may be greater than it appears, because it was not possible to test D738 in sensitization experiments as this mutant does not respond to capsaicin (see above).

We next used coimmunoprecipitation to test more directly whether some of the mutants identified in Figures 2 and $3 A$ inhibit interaction between TRPV1 and AKAP79 (Fig. 3C,D). A reduction in binding was observed for C742A and V745A, which had been identified in sensitization experiments (Fig. 2) and for D738A and C742A, identified in trafficking experiments (Fig. $3 A, B)$. However, no change was observed for R740A, which had 

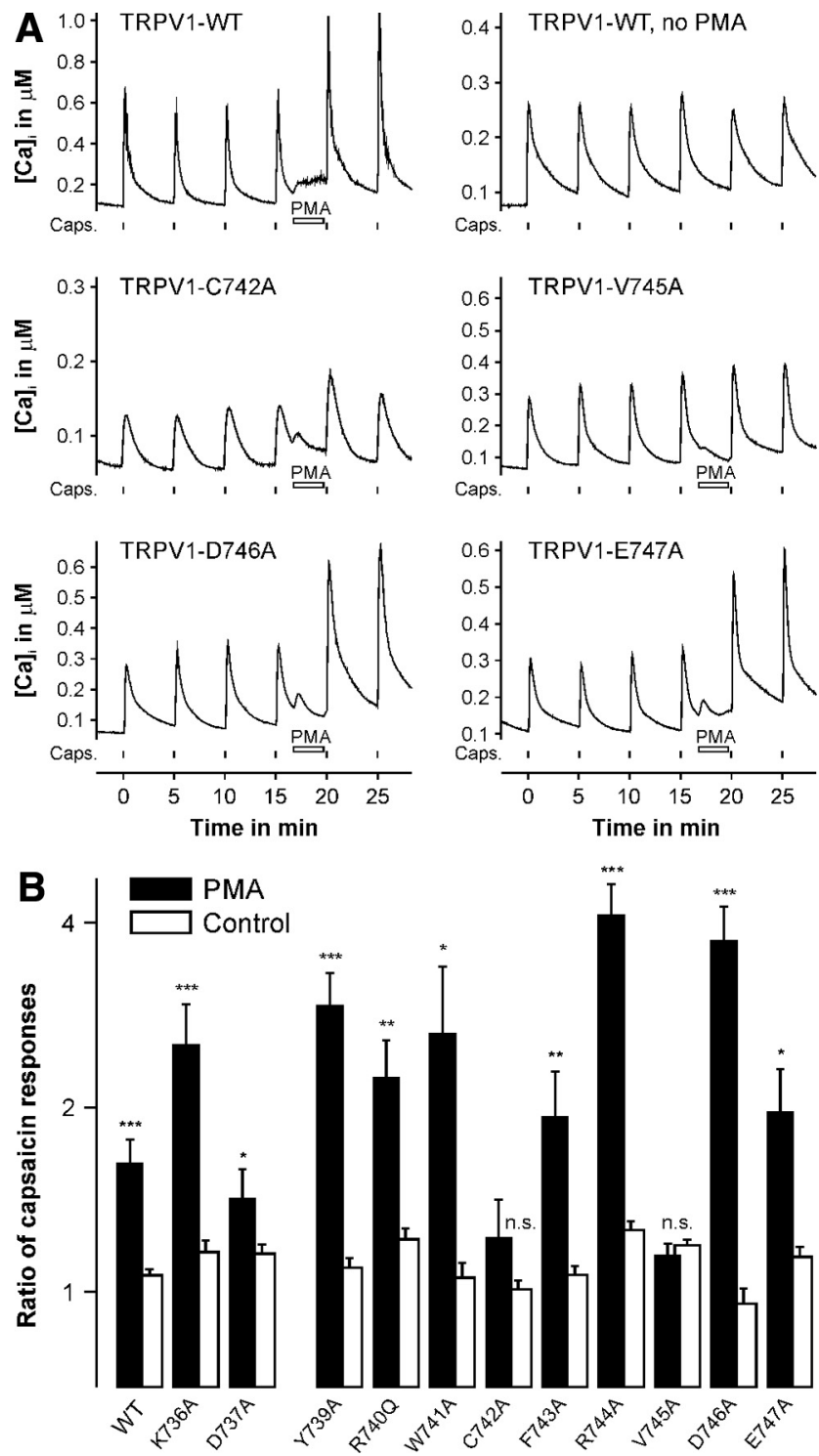

Figure 2. Sensitization of TRPV1 is disrupted by specific mutations in the AKAP79 binding site. $\boldsymbol{A}$, Sensitization of responses to capsaicin $(200 \mathrm{nM}, 1 \mathrm{~s})$ by PMA $(1 \mu \mathrm{M})$ in HEK293 cells transfected with WT TRPV1 (both with and without PMA), two mutants in which sensitization was ablated (C742A and V745A), and two mutants that had no significant effect on sensitization (D746A and E747A). Traces are averages \pm SEM of calcium signals from $n=52-230$ capsaicinresponsive cells per trace. $\boldsymbol{B}$, Ratio of calcium increase after PMA (6th to 4th capsaicin application, black bars) compared with control (ratio of 4th to 3 rd response). Bars show average \pm SEM. n.S., Not significant; ${ }^{*} p<0.05 ;{ }^{* *} p<0.01 ;{ }^{* * *} p<0.001$.

been identified as an interacting residue in trafficking experiments. Therefore, these results are in general terms consistent with the functional data obtained from sensitization and trafficking experiments, and the three approaches together identify a small group of amino acids, namely D738, R740, C742, and V745, as likely to be critical residues in mediating the binding of AKAP79 to TRPV1. The results also confirm previous studies that had identified this region of TRPV1 as the binding site for AKAP79.

\section{Disrupting AKAP79-TRPV1 interaction by}

competitive peptides

We next investigated the ability of peptide mimetics of the AKAP79 binding site on TRPV1 to antagonize sensitization
A
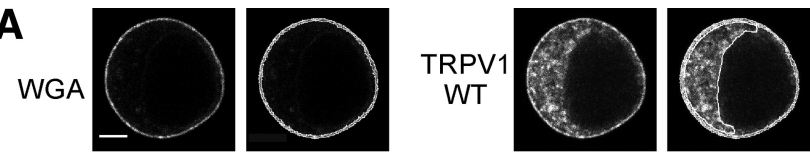

B

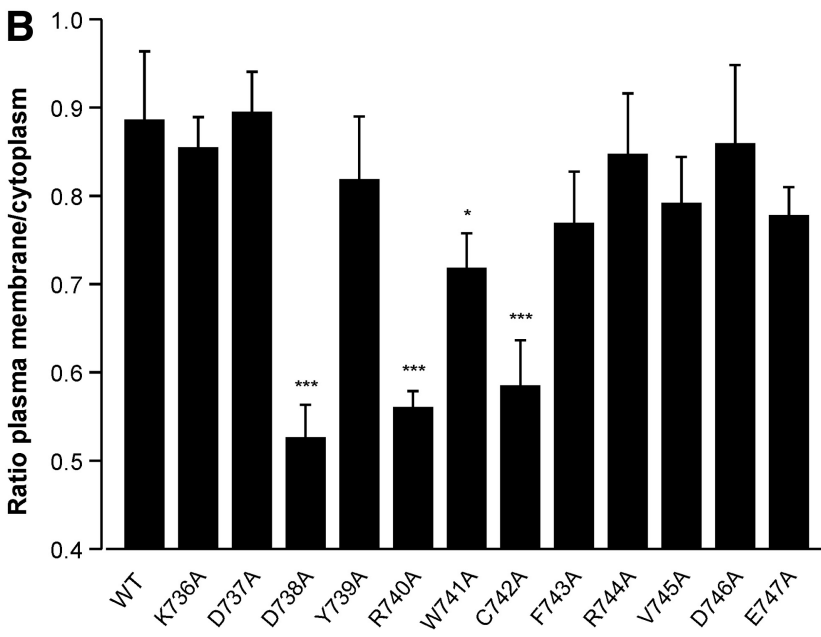

C

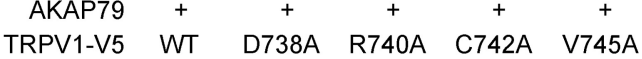

IP: V5

IB: AKAP79

IB: V5
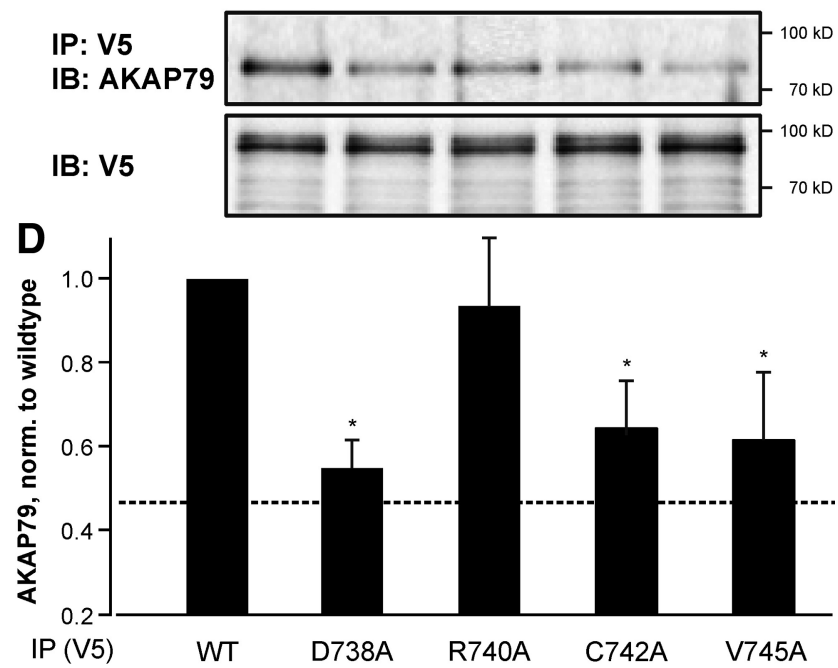

Figure 3. Trafficking of TRPV1 to the surface membrane and interaction with AKAP79 is reduced by specific mutations. $\boldsymbol{A}$, Images show HEK293 cell transfected with WT TRPV1. The image from a brief exposure to WGA (first panel) was used to create a juxtamembrane ROI (2nd panel) that was superimposed on the image of TRPV1 fluorescence (3rd panel) to measure TRPV1 levels at the membrane (4th panel, TRPV1 image plus ROI). A separate mask obtained from the thresholded fluorescence within the cell defined the cytoplasm excluding the nucleus (see 4th panel). $\boldsymbol{B}$, Ratio of mean fluorescence at the plasma membrane to cytoplasm for TRPV1 WT and alanine mutants, $n=12-30$. C, Coimmunoprecipitation of AKAP79 by TRPV1 mutants. Blot stripped and reprobed for TRPV1 (bottom blot). D, Intensity of AKAP79 band after immunoprecipitation, normalized to TRPV1 expression level and expressed relative to WT. Dotted line represents the nonspecific signal in the absence of TRPV1. Bars are average of four repetitions. IB, Immunoblot; IP, immunoprecipitation. ${ }^{*} p<0.05$; $^{* * *} p<0.001$.

caused by activation of PKC. We used whole-cell voltageclamped capsaicin-sensitive DRG neurons and allowed 13 min for the peptide to diffuse from the pipette into the cell before activating PKC with PMA, which in the absence of added peptide produced a substantial sensitization of membrane current carried by TRPV1. Note that sensitization was also seen with the inflammatory mediator bradykinin but was more pronounced with PMA, which more potently activates PKC (Fig. 4A,B). As 

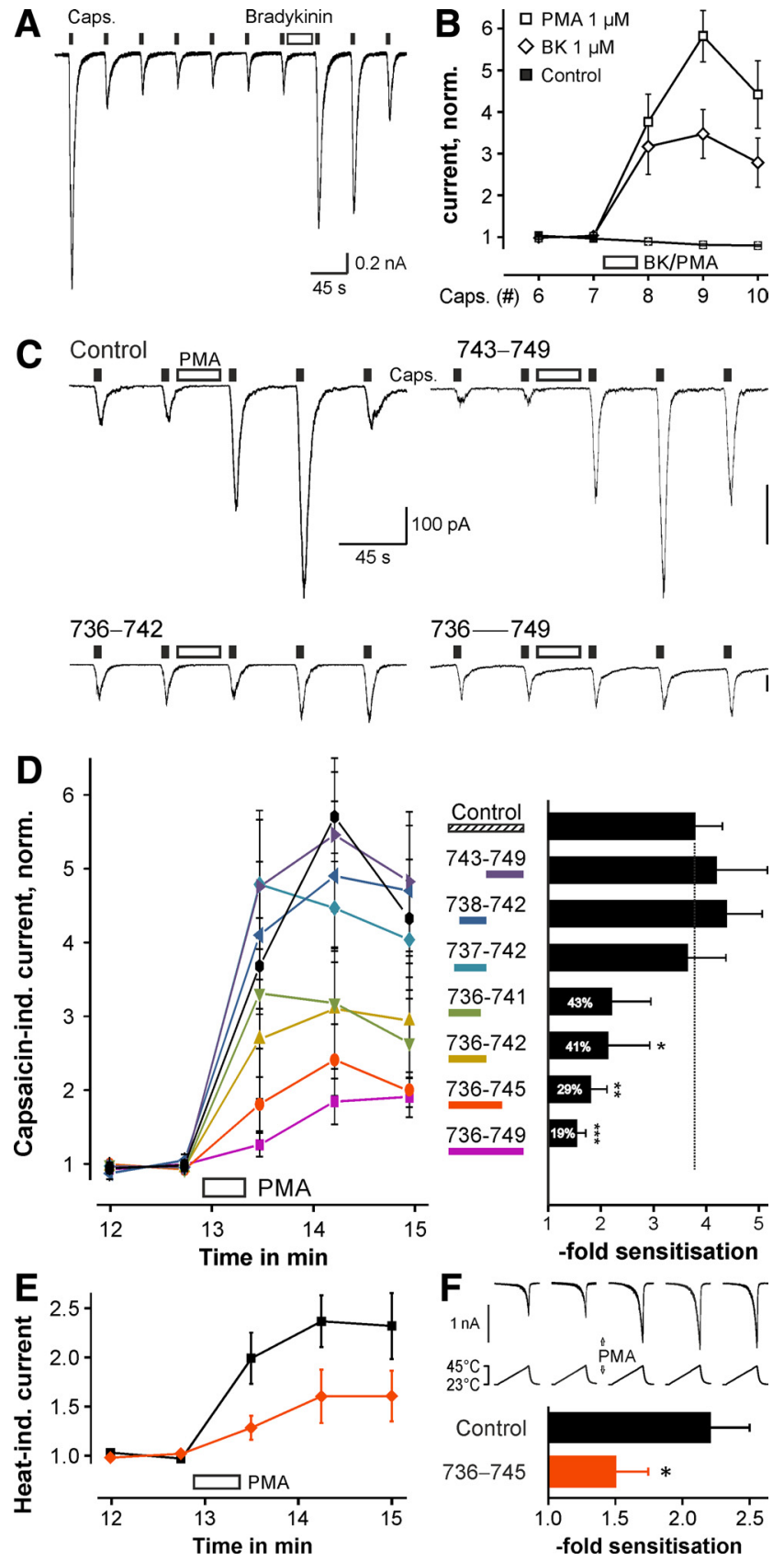

Figure 4. Intracellular peptides inhibit the PMA-induced sensitization of currents evoked by capsaicin in DRG neurons. $\boldsymbol{A}$, Representative voltage-clamp experiment showing that inward current evoked by capsaicin (Caps.; $200 \mathrm{~nm}$, application shown by black bars) is sensitized by bradykinin (BK; $1 \mu \mathrm{M}$, white bar). $\boldsymbol{B}$, Comparison of sensitization by PMA or bradykinin (30 s) compared with control. Note that PMA generated a more robust and less variable sensitization; the SD/mean was 0.41 for PMA compared with 0.60 for bradykinin ( $n=9-13)$. C, Sample traces showing effect of peptides corresponding to subsets of the TRPV1 AKAP79 binding site on sensitization of capsaicin by PMA. Peptides $(200 \mu \mathrm{m})$ were added to pipette solution and the cell was held in whole-cell configuration for $\sim 13$ min without negative pressure before application of PMA to allow diffusion of peptide into cytoplasm. $\boldsymbol{D}$, Peak current evoked by capsaicin $(100 \mathrm{~nm}, 5 \mathrm{~s})$, normalized to mean of last two stimuli before PMA. Location of peptide shown by colored bars. Mean sensitization over responses 8-10 shown in the right panel. ${ }^{*} p<0.05,{ }^{* *} p<0.01$, ${ }^{* * *} p<0.001$ compared with control, $n=8-16$. E, Sensitization of heat-evoked TRPV1 currents by PMA $(1 \mu \mathrm{M})$ was reduced with 736-745 peptide in the recording pipette. $\boldsymbol{F}$, Specimen of heat-evoked current and temperature ramp measured at the application tip. Heat ramps lasted $5 \mathrm{~s}$ and were applied every $45 \mathrm{~s}$. Bottom, Mean of peak responses to three heat stimulations after PMA (see $\boldsymbol{E}$ ), normalized to response before. ${ }^{*} p<0.05$ compared to control, $n=9$ each. shown previously (Zhang et al., 2008), the full-length 736-749 peptide caused strong inhibition of sensitization of TRPV1 $(p<$ 0.001, ANOVA, HSD post hoc test; Fig. 4C,D). Dividing this peptide into two showed that 736-742 gave significant inhibition $(p=0.041)$, whereas $743-749$ was ineffective (Fig. $4 C, D)$, suggesting that the main AKAP79 binding sites are in the $\mathrm{N}$-terminal half of the peptide. Significant inhibition was also observed with peptide 736-745 ( $p=0.002)$. These results agree with the results of site-directed mutagenesis, which had identified the region $738-745$ as critical. However, when we removed residue K736, which site-directed mutagenesis had not indicated to be critical, all inhibition was lost (peptides 737-742 and 738-742; Fig. 4D). A possible cause may be that a charged $\mathrm{N}$ terminal is present in the peptide but not in the protein, and removal of K736 uncovers an additional negative charge at D737 that may inhibit the ability of the peptide to compete for the TRPV1 binding site on AKAP79.

We also tested whether an inhibitory peptide is able to disrupt sensitization of TRPV1 when heat is the activating stimulus. Figure $4, E$ and $F$, shows that the inward current activated in DRG neurons by a brief heat ramp is sensitized by activation of PKC using PMA and that addition of the 736-745 peptide to the intracellular solution significantly inhibited sensitization $(p=0.028$, $U$ test, $n=9$ each).

From the combined results using site-directed mutagenesis and peptide antagonists, we identified the peptide sequence 736745 as a likely candidate for a possible analgesic effect on inflammatory hyperalgesia in vivo. To promote uptake across the neuronal cell membrane, we combined this inhibitory peptide with a domain of TAT (from the HIV transactivator of transcription, amino acids 47-57, YGRKKRRQRRR). We first tested the effectiveness of the TAT-coupled peptide when applied intracellularly, and we found that the inhibition of PKC-mediated sensitization was comparable with that of the unconjugated peptide, whereas a scrambled 736-745-TAT peptide (scramble-TAT) was ineffective (Fig. 5A-C). When the 736-745-TAT peptide was applied in the extracellular solution, at a much lower concentration $(5 \mu \mathrm{M})$ than had been used for intracellular application $(200 \mu \mathrm{M})$, the sensitization caused by PMA was not significantly different from zero, whereas in control experiments without peptide or when the scramble-TAT peptide was applied in the extracellular solution, a significant PKC-mediated sensitization was observed ( $p=0.005$ and $p=0.009$, respectively, Wilcoxon's matchedpairs test; Fig. $5 D, E$ ). These experiments show that the TATcoupled peptide accumulated within the cell and was able to inhibit PKC-mediated sensitization of TRPV1.

\section{Inhibition of sensitization in vivo}

Injection of Formalin into the plantar surface of a paw initiates a biphasic pain-related behavior, in which the first phase is attributable to direct activation of nociceptors, whereas the second phase results from sensitization of nociceptors by inflammatory mediators (Dubuisson and Dennis, 1977; Macpherson et al., 2007; McNamara et al., 2007). Pharmacological inhibition of TRPV1 reduces Formalin-induced behavioral responses (Tang et al., 2007), showing that sensitization of TRPV1 by inflammatory mediators is a significant contributor to pain behavior in the Formalin test.

We injected saline, 736-745-TAT $(10 \mu \mathrm{M})$, or scramble-TAT $(100 \mu \mathrm{M})$ into the plantar surface of mouse hindpaws $30 \mathrm{~min}$ before injection of Formalin. No differences were observed in the first phase of the Formalin test. However, in the second phase, 736-745-TAT suppressed pain-related behavior compared with saline $(p<0.001$; Fig. $6 A$, ANOVA, HSD post hoc test), whereas a 10-fold concentrated 

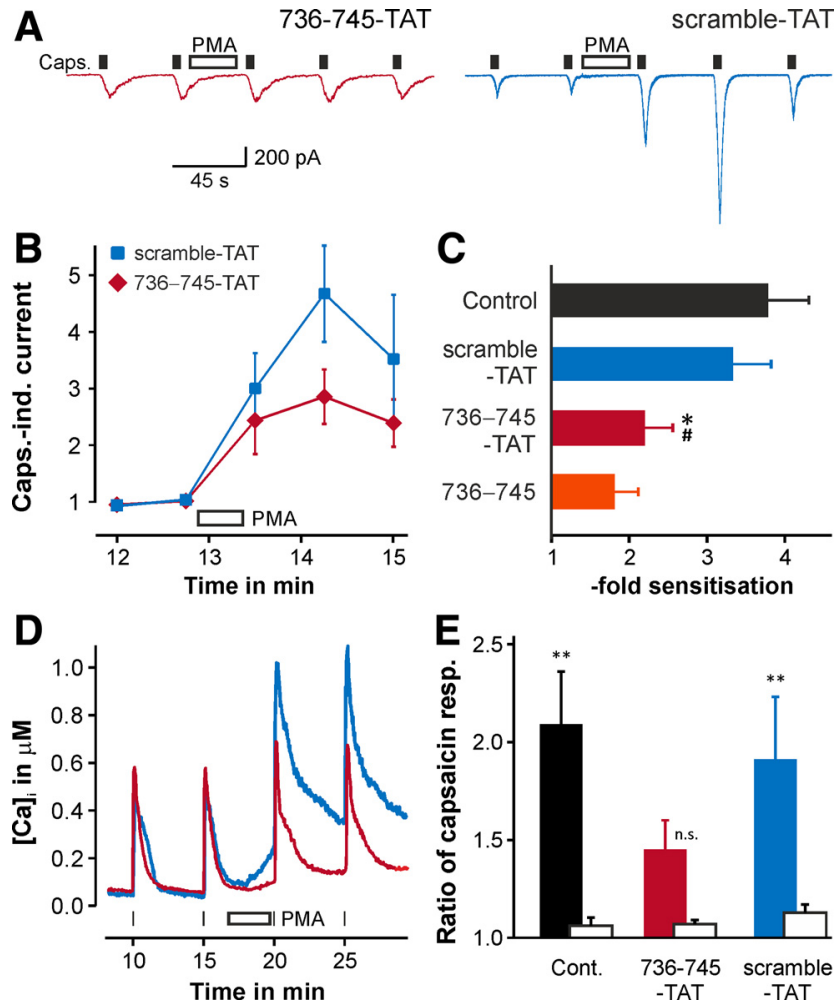

Figure 5. TAT-conjugated 736-745 peptide inhibits TRPV1 sensitization. $\boldsymbol{A}$, Example trace showing PMA-induced sensitization of TRPV1 in DRG neurons with intracellular application of 736-745-TAT or scramble-TAT (200 $\mu \mathrm{m}$ ) in patch pipette; protocol as in Figure 4. Time course $(\boldsymbol{B})$ and average of TRPV1 sensitization $(\boldsymbol{C})$ in DRG neurons with intracellular addition of TATconjugated and unconjugated peptides, $n=6-16 .{ }^{*}{ }^{*} p<0.05$ compared to control and scramble-TAT, respectively. Data for control and 736-745 taken from Figure 4. D, HEK293 cells transfected with TRPV1 and loaded with fura-2 AM for $30 \mathrm{~min}$, exposed to extracellular TATconjugated peptide ( $5 \mu \mathrm{m}$ ) for $20 \mathrm{~min}$, and subsequently exposed to capsaicin pulses as in Figure 2, $n=65-128$. $\boldsymbol{E}$, Average sensitization ratio after application of PMA (filled bars) compared with control (open bars). Significant sensitization was observed in control experiments without peptide and in experiments with scramble-TAT $\left({ }^{* *} p<0.01\right)$ but not with 736-745-TAT. n.S., Not significant.

scramble-TAT injection had no effect. In a second model, we directly activated PKC by injecting PMA, which causes a milder phase of delayed nociceptive behavior similar in time course to the second phase of the Formalin test (Ferreira et al., 2005). In agreement with the data from the Formalin test, 736-745-TAT suppressed pain behavior in the interval 10-25 min after injection when compared with saline ( $p=0.003$, ANOVA, HSD post hoc test), whereas scrambleTAT was ineffective (Fig. 6B).

Finally, we investigated the effect of the 736-745-TAT peptide on inflammatory heat hyperalgesia using the Hargreaves test (Fig. $6 C)$. Intraplantar injection of carrageenan caused a reduction in the paw-withdrawal latency to a radiant heat stimulus when compared with saline ( $p<0.001$, ANOVA, HSD post hoc test). Preinjection of 736-745-TAT significantly reduced heat hyperalgesia when compared with preinjection of either saline $(p<0.001)$ or scramble-TAT $(p<0.001)$. Notably, preinjection of 736-745-TAT did not affect paw-withdrawal latencies in the absence of inflammation (Fig. 6C).

\section{Discussion}

AKAP79 has been shown to interact with several other receptors and channels, such as the $\beta 2$-adrenergic receptor, KCNQ2 channels, AMPA and NMDA receptors, and L-type voltage-gated $\mathrm{Ca}^{2+}$ channels (for review, see Beene and Scott, 2007). The inter-
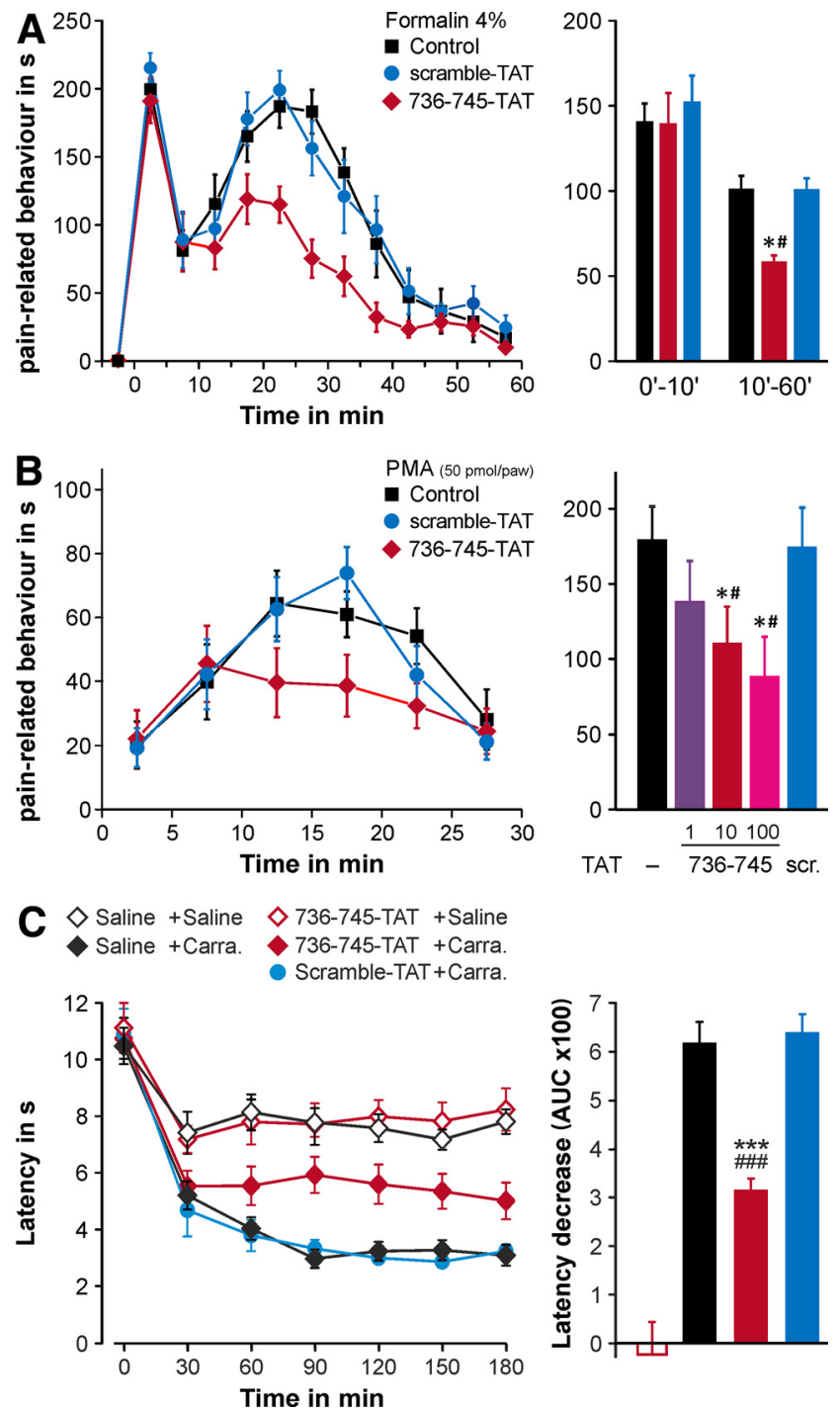

Figure 6. 736-745-TAT suppresses pain-related behavior in mice. A, Formalin test of inflammatory hyperalgesia. TAT-conjugated peptides injected in plantar hindpaw, followed by Formalin (4\%, 30 min later) at the same site. No difference was found in phase I ( $0-10 \mathrm{~min})$, but 736-745-TAT (10 $\mu \mathrm{m}, 20 \mu \mathrm{l})$ suppressed phase II (10-60 min) compared with both saline and scramble-TAT $(100 \mu \mathrm{m}, 20 \mu \mathrm{l}) ; p<0.05$ compared with control $\left(^{*}\right)$ or scramble-TAT (\#), $n=$ 9 per group. $\boldsymbol{B}$, PMA test of inflammatory hyperalgesia. TAT-conjugated peptides coinjected with PMA ( $50 \mathrm{pmol} / \mathrm{hindpaw}$ ). At $10-25$ min after injection, licking of paw was attenuated by 736-745-TAT (1, 10, and $100 \mu \mathrm{m}$ as indicated). $p<0.05$ compared with controls $\left(^{*}\right)$ and scramble-TAT (\#), $n=8-12$ per group. C, 736-745-TAT blocks inflammatory thermal hyperalgesia without affecting acute thresholds. 736-745-TAT, scramble-TAT (10 $\mu \mathrm{m}$ in saline), or saline were injected 30 min before $\lambda$-carrageenan (Carr.; $2 \%, 20 \mu l$ ) or saline, $n=12$ per group. Ordinate shows latency for paw withdrawal to radiant heat after $\lambda$-carrageenan injection, baseline measured before injection ( $0 \mathrm{~min}$ ). Right panel shows difference of area under the curve (AUC) between test samples and saline-carrageenan inflammation control (30-180

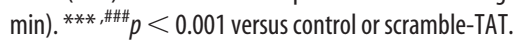

action of AKAP79 with AMPA and NMDA glutamate receptors has become an important topic of investigation in synaptic plasticity involved in memory and learning. AKAP79 is associated with the AMPA glutamate receptor 1 (GluR1) through the synapse-associated protein 97 (Colledge et al., 2000). The interaction is thought to mediate long-term potentiation by facilitating the phosphorylation of Ser845 on GluR1, thus enhancing AMPA currents (Roche et al., 1996; Banke et al., 2000). AKAP79 has also been shown to mediate the basal phosphorylation and dephosphorylation of AMPA GluR1 receptors in a process 
thought to underlie long-term depression (Tavalin et al., 2002). Moreover, activation of NMDA receptors can regulate the synaptic localization of AKAP79 through activation of calmodulin and remodeling of F-actin (Gomez et al., 2002) and can regulate AMPA receptor endocytosis through the interaction of AKAP79 and the postsynaptic density protein 95 (Bhattacharyya et al., 2009). More recently, it has been shown that NMDA receptor activation in trigeminal sensory neurons modulates AKAP150/ 79-mediated phosphorylation of TRPV1 by PKA and PKC (Lee et al., 2012), suggesting that TRPV1, NMDA receptor, and AKAP150/79 form a signaling complex that could be involved in the underlying sensitization of sensory neurons in inflammatory and neuropathic pain.

The work reported here extends a previous study (Zhang et al., 2008) in which a critical role for AKAP79 in sensitization of TRPV1 in primary nociceptive neurons was shown. We used three independent methods to define critical amino acids mediating binding to AKAP79 in the C-terminal of TRPV1. We activated PKC by application of PMA and explored the effect of mutations on sensitization of TRPV1, we examined the ability of mutations to inhibit translocation of TRPV1 to the cell-surface membrane, and we tested the interaction between TRPV1 and AKAP79 directly by coimmunoprecipitation. Amino acids identified as critical on these three measures were overlapping but not completely identical. Thus, C742A and V745A had a clear effect on sensitization (Fig. 2B); D738A could not be tested because the mutant made the channel unresponsive to capsaicin (Fig. 1), for unknown reasons. In the trafficking experiment, D738A, R740A, and $\mathrm{C} 742 \mathrm{~A}$ were identified. Coimmunoprecipitation identified D738A, C742A, and V745A but not R740A as affecting the direct interaction. The reasons for the discrepancies are not entirely clear, because previous work has shown that both sensitization and trafficking are dependent on binding of AKAP79 to TRPV1 and thus on alignment of PKC and PKA adjacent to the relevant phosphorylation sites (Zhang et al., 2008). Mutations affecting binding should therefore equally affect sensitization and trafficking. A probable explanation is a certain amount of experimental variability rather than a defect in the underlying hypothesis.

The combination of these three approaches identified a small group of amino acids, namely D738, R740, C742, and V745, as likely critical residues mediating the binding of AKAP79 to TRPV1 (Fig. 7). The first three critical residues alternate with noncritical residues, suggesting a $\beta$-sheet configuration for the binding domain of AKAP79 on TRPV1, but structural prediction programs do not strongly favor a $\beta$-sheet conformation for this region of TRPV1.

Peptides mimicking portions of the TRPV1 AKAP79 binding domain were loaded into DRG neurons via the patch-clamp pipette and tested for their ability to reduce sensitization to both capsaicin and heat. A significant inhibition of sensitization was obtained with a short 736-742 peptide, although the slightly longer 736-745 decapeptide was more effective and was chosen for subsequent studies. The 736-745 domain is the most polar part of the intracellular C terminus (http://web.expasy.org/protscale, Grantham, 7 aa window) and overlaps with all the critical amino acids identified above. When coupled to a TAT peptide, which confers permeability across the cell membrane, we found that this peptide could be applied in the extracellular medium to effectively inhibit sensitization of TRPV1. Critically, the peptide had no effect on the activation of TRPV1 by capsaicin and so does not interfere with the normal gating of TRPV1.

We next chose three models of inflammatory hyperalgesia for in vivo testing of the TAT-coupled inhibitory peptide. Injection

\section{TRPV1 KD $\stackrel{*}{*} \stackrel{*}{\mathrm{R} W C} \mathrm{*} F \stackrel{*}{*} \mathrm{DEVN}$ TRPV4 TPDRRWCFRVDEVN TRPV2 TPDRRWCFRVEEVN TRPV3 EDDFRLCLRINEVK}

Figure 7. Key residues for the TRPV1-AKAP79 interaction are unique to TRPV1. Within the human genome, more than five consecutive amino acids of the TRPV1 736-749 range are only shared by TRPV4 and TRPV2 (http://blast.ncbi.nlm.nih.gov). Important residues for the inhibition of sensitization as determined by site-directed mutagenesis (indicated by *) and by antagonist peptides (see Fig. 4), are only found in TRPV1. Shaded background indicates identical amino acids. The human 736-749 TRPV1 sequence range is highly conserved and is identical for Macaca fascicularis, Crotalus atrox, Carollia brevicauda, Canis lupus familiaris, Bos taurus, Scapanus orarius, Rattus norvegicus, and Cavia porcellus; one amino acid difference is found in Mus musculus, Oryctolagus cuniculus, Xenopus laevis, and Gallus gallus.

of Formalin into a hindpaw initiates an early phase of pain behavior, caused by direct activation of nociceptors, followed by a second phase that depends on the release of inflammatory mediators such as prostaglandin $\mathrm{E}_{2}$ and bradykinin, which activate PKA and PKC and are therefore likely to sensitize TRPV1 via an AKAP79-dependent mechanism (Dubuisson and Dennis, 1977; Macpherson et al., 2007; McNamara et al., 2007). In agreement with this prediction, we found that preinjection of the TATcoupled peptide reduced pain-related behavior in the second but not the first phase. We also showed that the peptide inhibited pain behavior using a more specific test, in which injection of PMA, a selective PKC activator, caused pain behavior with a time course similar to that of the second phase of the Formalin test. This finding supports the view that PMA does not directly activate TRPV1, because it causes no early phase of pain behavior similar to that seen in the Formalin test but instead causes a delayed increase in TRPV1 open probability by a PKC-dependent mechanism (Studer and McNaughton, 2010). In a third model, we induced heat hyperalgesia by injection of carrageenan, which causes a mild inflammation, and showed that the hyperalgesia was reduced by preinjection of the TAT-coupled peptide. In summary, these experiments show that peptides antagonizing the interaction between AKAP79 and TRPV1 can act as effective analgesics in vivo. However, we note that, although the in vivo experiments are consistent with a direct inhibition of TRPV1AKAP79 binding, we cannot completely exclude the possibility that the inhibitory peptide may also prevent AKAP79 from interacting with other substrates. There is significant homology between the TRPV1 736-745 domain and corresponding domains in TRPV4 and TRPV2 and some limited homology with TRPV3, but there is no homology with other ion channels (Fig. 7), suggesting that antagonism of the binding between TRPV1 and AKAP79 will be limited to the TRPV family of ion channels. In the case of TRPV4, AKAP79 has been shown to bind to and potentiate its activation (Zhang et al., 2008; Fan et al., 2009).

A cell-permeable peptide disrupting the interaction between collapsin response mediator protein 2 and the presynaptic $\mathrm{Ca}_{\mathrm{v}} 2.2$ voltage-dependent calcium channel has also been shown to reduce inflammatory pain (Brittain et al., 2011). However, the peptide used in this study inhibited both the first and the second phase of pain behavior in the Formalin test, implying an effect on both acute and inflammatory pain, unlike the TRPV1 736-745TAT peptide used in the present study that only affects the second phase. In a second paper, a peptide competing with the interaction of Src kinase with NADH (nicotinamide adenine dinucleotide) dehydrogenase subunit 2 (ND2), the adaptor protein 
through which Src interacts with NMDA, also diminished inflammatory pain (Liu et al., 2008). Src has been shown to mediate the sensitization of TRPV1 by increasing its trafficking to the plasma membrane (Zhang et al., 2005), and it would therefore be interesting to assess whether the effects of antagonizing the interaction of Src with ND2 is also mediated via TRPV1.

The experiments reported here demonstrate that a series of key amino acids in the 738-745 C-terminal domain of TRPV1 is required for interaction with AKAP79/150 and consequently for sensitization mediated by inflammatory mediators that activate PKA and PKC as downstream targets. We found that synthetic peptide mimetics of this binding domain reduced sensitization both in vitro and in vivo but without changing the baseline sensitivity of TRPV1. These results suggest that preventing sensitization of TRPV1 by antagonizing the interaction with AKAP79 will have value as an analgesic strategy and that the approach of interfering with the interaction between AKAP79 and TRPV1, rather than simply blocking TRPV1, may offer a promising therapeutic route for novel analgesics.

\section{References}

Banke TG, Bowie D, Lee H, Huganir RL, Schousboe A, Traynelis SF (2000) Control of GluR1 AMPA receptor function by cAMP-dependent protein kinase. J Neurosci 20:89-102. Medline

Beene DL, Scott JD (2007) A-kinase anchoring proteins take shape. Curr Opin Cell Biol 19:192-198. CrossRef Medline

Bhattacharyya S, Biou V, Xu W, Schlüter O, Malenka RC (2009) A critical role for PSD-95/AKAP interactions in endocytosis of synaptic AMPA receptors. Nat Neurosci 12:172-181. CrossRef Medline

Bonnington JK, McNaughton PA (2003) Signalling pathways involved in the sensitisation of mouse nociceptive neurones by nerve growth factor. J Physiol 551:433-446. CrossRef Medline

Brandao KE, Dell'Acqua ML, Levinson SR (2012) A-kinase anchoring protein 150 expression in a specific subset of T. J Comp Neurol 520:81-99. CrossRef Medline

Brittain JM, Duarte DB, Wilson SM, Zhu W, Ballard C, Johnson PL, Liu N, Xiong W, Ripsch MS, Wang Y, Fehrenbacher JC, Fitz SD, Khanna M, Park CK, Schmutzler BS, Cheon BM, Due MR, Brustovetsky T, Ashpole NM, Hudmon A, et al. (2011) Suppression of inflammatory and neuropathic pain by uncoupling CRMP-2 from the presynaptic $\mathrm{Ca}(2)(+)$ channel complex. Nat Med 17:822-829. CrossRef Medline

Caterina MJ, Schumacher MA, Tominaga M, Rosen TA, Levine JD, Julius D (1997) The capsaicin receptor: a heat-activated ion channel in the pain pathway. Nature 389:816-824. CrossRef Medline

Caterina MJ, Leffler A, Malmberg AB, Martin WJ, Trafton J, Petersen-Zeitz KR, Koltzenburg M, Basbaum AI, Julius D (2000) Impaired nociception and pain sensation in mice lacking the capsaicin receptor. Science 288: 306-313. CrossRef Medline

Cesare P, McNaughton P (1996) A novel heat-activated current in nociceptive neurons and its sensitization by bradykinin. Proc Natl Acad Sci U S A 93:15435-15439. Medline

Colledge M, Dean RA, Scott GK, Langeberg LK, Huganir RL, Scott JD (2000) Targeting of PKA to glutamate receptors through a MAGUK-AKAP complex. Neuron 27:107-119. CrossRef Medline

Davis JB, Gray J, Gunthorpe MJ, Hatcher JP, Davey PT, Overend P, Harries MH, Latcham J, Clapham C, Atkinson K, Hughes SA, Rance K, Grau E, Harper AJ, Pugh PL, Rogers DC, Bingham S, Randall A, Sheardown SA (2000) Vanilloid receptor-1 is essential for inflammatory thermal hyperalgesia. Nature 405:183-187. CrossRef Medline

Dittert I, Benedikt J, Vyklick ý L, Zimmermann K, Reeh PW, Vlachov á V (2006) Improved superfusion technique for rapid cooling or heating of cultured cells under patch-clamp conditions. J Neurosci Methods 151:178-185. CrossRef Medline

Dubuisson D, Dennis SG (1977) The formalin test: a quantitative study of the analgesic effects of morphine, meperidine, and brain stem stimulation in rats and cats. Pain 4:161-174. Medline

Fan HC, Zhang X, McNaughton PA (2009) Activation of the TRPV4 ion channel is enhanced by phosphorylation. J Biol Chem 284:27884-27891. CrossRef Medline
Ferreira J, Triches KM, Medeiros R, Calixto JB (2005) Mechanisms involved in the nociception produced by peripheral protein kinase $\mathrm{c}$ activation in mice. Pain 117:171-181. CrossRef Medline

Fischer MJM, Mak SWY, McNaughton PA (2010) Sensitisation of nociceptors: what are ion channels doing? Open Pain J 3:82-96.

Gavva NR, Bannon AW, Surapaneni S, Hovland DN Jr, Lehto SG, Gore A, Juan T, Deng H, Han B, Klionsky L, Kuang R, Le A, Tamir R, Wang J, Youngblood B, Zhu D, Norman MH, Magal E, Treanor JJ, Louis JC (2007) The vanilloid receptor TRPV1 is tonically activated in vivo and involved in body temperature regulation. J Neurosci 27:3366-3374. CrossRef Medline

Gomez LL, Alam S, Smith KE, Horne E, Dell'Acqua ML (2002) Regulation of A-kinase anchoring protein 79/150-cAMP-dependent protein kinase postsynaptic targeting by NMDA receptor activation of calcineurin and remodeling of dendritic actin. J Neurosci 22:7027-7044. Medline

Grynkiewicz G, Poenie M, Tsien RY (1985) A new generation of $\mathrm{Ca}^{2+}$ indicators with greatly improved fluorescence properties. J Biol Chem 260: 3440-3450. Medline

Jeske NA, Patwardhan AM, Ruparel NB, Akopian AN, Shapiro MS, Henry MA (2009) A-kinase anchoring protein 150 controls protein kinase C-mediated phosphorylation and sensitization of TRPV1. Pain 146:301307. CrossRef Medline

Lee J, Chung MK, Ro JY (2012) Activation of NMDA receptors leads to phosphorylation of TRPV1 $\$ 800$ by protein kinase C and A-kinase anchoring protein 150 in rat trigeminal ganglia. Biochem Biophys Res Commun 424:358-363. CrossRef Medline

Liu XJ, Gingrich JR, Vargas-Caballero M, Dong YN, Sengar A, Beggs S, Wang SH, Ding HK, Frankland PW, Salter MW (2008) Treatment of inflammatory and neuropathic pain by uncoupling Src from the NMDA receptor complex. Nat Med 14:1325-1332. CrossRef Medline

Lu SG, Zhang X, Gold MS (2006) Intracellular calcium regulation among subpopulations of rat dorsal root ganglion neurons. J Physiol 577:169-190. CrossRef Medline

Macpherson LJ, Xiao B, Kwan KY, Petrus MJ, Dubin AE, Hwang S, Cravatt B, Corey DP, Patapoutian A (2007) An ion channel essential for sensing chemical damage. J Neurosci 27:11412-11415. CrossRef Medline

McNamara CR, Mandel-Brehm J, Bautista DM, Siemens J, Deranian KL, Zhao M, Hayward NJ, Chong JA, Julius D, Moran MM, Fanger CM (2007) TRPA1 mediates formalin-induced pain. Proc Natl Acad Sci U S A 104:13525-13530. CrossRef Medline

Papakosta M, Dalle C, Haythornthwaite A, Cao L, Stevens EB, Burgess G, Russell R, Cox PJ, Phillips SC, Grimm C (2011) The chimeric approach reveals that differences in the TRPV1 pore domain determine speciesspecific sensitivity to block of heat activation. J Biol Chem 286:3966339672. CrossRef Medline

Roche KW, O’Brien RJ, Mammen AL, Bernhardt J, Huganir RL (1996) Characterization of multiple phosphorylation sites on the AMPA receptor GluR1 subunit. Neuron 16:1179-1188. CrossRef Medline

Sanderson JL, Dell'Acqua ML (2011) AKAP signaling complexes in regulation of excitatory synaptic plasticity. Neuroscientist 17:321-336. CrossRef Medline

Schnizler K, Shutov LP, Van Kanegan MJ, Merrill MA, Nichols B, McKnight GS, Strack S, Hell JW, Usachev YM (2008) Protein kinase A anchoring via AKAP150 is essential for TRPV1 modulation by forskolin and prostaglandin E2 in mouse sensory neurons. J Neurosci 28:4904-4917. CrossRef Medline

Studer M, McNaughton PA (2010) Modulation of single-channel properties of TRPV1 by phosphorylation. J Physiol 588:3743-3756. CrossRef Medline

Tang L, Chen Y, Chen Z, Blumberg PM, Kozikowski AP, Wang ZJ (2007) Antinociceptive pharmacology of $N$-(4-chlorobenzyl)- $N^{\prime}$ - (4-hydroxy-3iodo-5-methoxybenzyl) thiourea, a high-affinity competitive antagonist of the transient receptor potential vanilloid 1 receptor. J Pharmacol Exp Ther 321:791-798. CrossRef Medline

Tavalin SJ, Colledge M, Hell JW, Langeberg LK, Huganir RL, Scott JD (2002) Regulation of GluR1 by the A-kinase anchoring protein 79 (AKAP79) signaling complex shares properties with long-term depression. J Neurosci 22:3044-3051. Medline

Vay L, Gu C, McNaughton PA (2012) The thermo-TRP ion channel family: properties and therapeutic implications. Br J Pharmacol 165:787-801. CrossRef Medline

Welch EJ, Jones BW, Scott JD (2010) Networking with AKAPs: context- 
dependent regulation of anchored enzymes. Mol Interv 10:86-97. CrossRef Medline

Zhang X, Huang J, McNaughton PA (2005) NGF rapidly increases membrane expression of TRPV1 heat-gated ion channels. EMBO J 24:42114223. CrossRef Medline
Zhang X, Li L, McNaughton PA (2008) Proinflammatory mediators modulate the heat-activated ion channel TRPV1 via the scaffolding protein AKAP79/150. Neuron 59:450-461. CrossRef Medline 